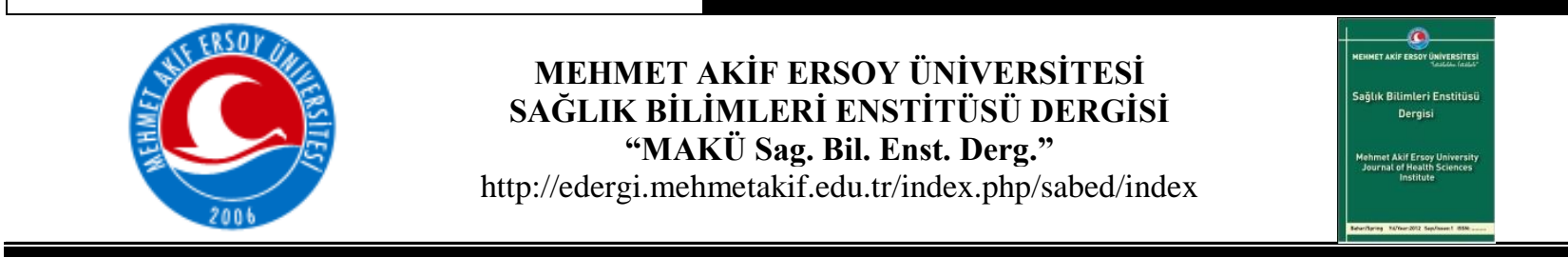

\title{
Hemşin Koyunlarında Metapodium'ların Morfometrik ve Stereolojik İncelenmesi
}

\author{
The Morphometric and Stereologic Investigation of Metapodium in Male \\ Hemshin Sheep \\ İftar Gürbüz ${ }^{1}$, Yasin Demiraslan ${ }^{1}$, Gülseren Kırbaş², Kadir Aslan² \\ ${ }^{1}$ Mehmet Akif Ersoy Üniversitesi Veteriner Fakültesi Anatomi Anabilim Dalı, BURDUR, TÜRKIYYE \\ ${ }^{2}$ Kafkas Üniversitesi Veteriner Fakültesi Anatomi Anabilim Dalı, KARS, TÜRKIYYE
}

\begin{abstract}
This study was aimed to evaluate metapodium as morphometrical and sterological in the Hemshin sheep breeds. In the study, 10 male Hemshin sheep's metapodium with oneyear age were used. Following maceration, 16 morphometrical and 3 stereological, totally 19 measurements were obtained from each metapodium. Stereologically, cavum medullare and bone volume were measured using the Cavalieri principle. The metapodial volumes were calculated by collecting these two values. In the study, the maximum lengt of metacarpus and metatarsus were determined as $134.40 \mathrm{~mm}$ and $139.16 \mathrm{~mm}$, respectively. According to the obtained data, the volume of metacarpus and metatarsus were determined as $26.88 \mathrm{~cm}^{3}$ and $36.39 \mathrm{~cm}^{3}$, respectively. The difference between metacarpus and metatarsus were found statistically significant when compared with total bone volume and bone volume $(\mathrm{P}<0.05)$.

As a result, it is thought that the study will be contribute to the morphometric and stereological studies on the metapodium in sheep and will be a source of data for archaeological excavations.
\end{abstract}

Key words: Hemshin Sheep, metapodium, stereology

Yazışma Adresi: Dr. Öğretim Üyesi Yasin Demiraslan Mehmet Akif Ersoy Üniversitesi, Veteriner Fakültesi, Anatomi Anabilim Dalı, 15030, BURDUR, TÜRKIYE

E-posta: yasindemiraslan@ hotmail.com

Tel: +9002482132162

Kaynak göstermek için: Gürbüz İ, Demiraslan Y, Kırbaş G, Aslan K. 2018. Hemşin Koyunlarında Metapodium'ların Morfometrik ve Stereolojik İncelenmesi. MAKÜ Sag. Bil. Enst. Derg. 6(1): 1-14. doi: 10.24998/maeusabed.397381

\begin{abstract}
Öz: Çalışmada Hemşin koyun ırkında metapodium'ların morfometrik ve stereolojik olarak değerlendirilmesi amaçlandi. $\mathrm{Bu}$ amaçla 1 yaşında 10 adet erkek Hemşin koyunu metapodium'u kullanıldı. Maserasyondan sonra metapodium'lardan 16 morfometrik, 3 stereolojik toplam 19 adet ölçü alındı. Stereolojik olarak cavum medullare ve kemik hacmi Cavalieri prensibi kullanılarak ölçüldü. Elde edilen bu iki değer toplanarak metapodial hacme ulaşıldı. Çalışmada maksimum uzunluk metacarpus'ta ortalama $134.40 \mathrm{~mm}$, metatarsus'ta ortalama $139.16 \mathrm{~mm}$ olarak belirlendi. Elde edilen verilere göre, metacarpus hacmi ortalama $26.88 \mathrm{~cm}^{3}$, metatarsus hacmi ortalama $36.39 \mathrm{~cm}^{3}$ olarak tespit edildi. Metacarpus ve metatarsus toplam kemik hacmi ve kemik hacmi bakımından karşılaştırıldığında farkın istatistiksel olarak önemli olduğu belirlendi $(\mathrm{P}<0.05)$. Sonuç olarak çalışmanın koyunlarda metapodium üzerinde yapılacak morfometrik ve stereolojik çalışmalara katkı sağlayacağı ve arkeolojik kazılarda veri kaynağ1 oluşturacağ 1 düşünülmektedir.
\end{abstract}

Anahtar sözcükler: Hemşin Koyunu, metapodium, stereoloji

Geliş Tarihi: 21.02.2018～Kabul Tarihi: 26.06.2018 


\section{Giriş}

Et, süt ve yapağı verimi amacıyla kombine bir ırk olarak yetiştirilen Hemşin koyunları Doğu Karadeniz Bölgesinin başlıca koyun ırkını oluşturmaktadır. Hemşin koyunu genel olarak kısa boyunlu, dar gögüslüdür. Sağrı ve bacakları orta yüksekliktedir. Bazıları küçük kulaklı bazıları ise kulaksızdır. Siyah ve kirli beyaz renkli Hemşin koyunları bulunmaktadır. Yüz ve baş genel olarak yapağılı, arka bacaklar ise ince yapağı ile kaplıdır. Kuyruk yapısı tek parçadır. Kuyruğun dip kısmı geniş olup tarsal bölgeye doğru daralır ve uç kısmında ince bir parça bulunur (Ziraatkent, 2018).

Kemikler hayvanlarda önemli yağ kaynaklarındandır. Hayvan kemiklerindeki yağ deposunu ise cavum medullare ve substantia spongiosa'daki yağlar oluşturmaktadır. Literatürde yetersiz beslenen ve vücut yağı az olan hayvanlarda medullar kemik yağının fazla olacağı bildirilmiştir (Outram, 2003). Uzun süreli açlık durumunda ise medullar ve spongioz yağların metabolize edileceği belirtilmiştir (Brokees ve ark., 1977). Currey (2002)'e göre bir hayvan sağlıklı ve iyi bir kondüsyona sahip ise mandibula ve uzun kemiklerinin cavum medullare'si kemik yağı bakımından diğer hayvanlardan (kötü kondüsyonlu ve hasta) üstün olabilmektedir.

Literatürde koyun ve sığır metapodium'larının incelenerek koyunun evcilleştirilme tarihine dair verilerin belirlenebileceği ve fosiller üzerinden popülasyona dair yorumlar türetilebileceği öne sürülmüştür (Guintard ve Lallemand, 2003; Lallemand, 2002). Arkeolojik kazılar sırasında elde edilen kemiklerin hayvan morfolojisi açısından önemi tartışılmazdır. Bu anlamda Neolitik döneme ait koyun ve keçi kemiklerinin ayrımında metapodium'ların kullanıldığı bildirilmektedir (Rowley-Conwy, 1998). Bu bilgileri destekler nitelikte bir çalışmada keçinin metapodium'larının koyundan daha kısa ve geniş olduğu belirtilmektedir (Boessneck, 1969). Pazvant ve ark. (2015) ve Onar ve ark. (2008) İstanbul ve Doğu Anadolu Bölgesi'nde yapılan kazılardan elde edilen koyun ve keçi metapodium'larını osteometrik olarak incelemişlerdir. Shetland koyunlarında yapılan bir çalışmada, zayıf kondüsyonlu koyunların, ortalama kondüsyonlu ve iyi kondüsyonlulara göre osteometrik ölçüler bakımından daha küçük olduğu belirtilmiştir (Davis, 1996). Alpak ve ark. (2009) yaptığı çalışmada Morkaraman koyunu uzun kemiklerini morfometrik yönden değerlendirmiş ve bir takım bulgular ortaya koymuştur. Yine başka bir çalışmada Çakır ve ark. (1998) karaca metapodiumlarını makroanatomik ve morfometrik olarak incelemişlerdir. 
Kemiklerdeki kemik iliği miktarının değerlendirilmesinde cavum medullare hacminin bilinmesi gerekmektedir (Outram, 2002). Volüm hesaplamada sıklıkla başvurulan yöntem ise 'altın standart' olan stereolojik metotlardır. Stereolojik metotlardan ise en çok kullanılanı "Cavalieri prensibi” dir. Bu prensip daha çok beyin ve karaciğer gibi organların hacminin tahmininde kullanılsa da (Avendano ve ark., 1995; Garcia-Finana ve ark., 2003) bilgisayarlı tomografi ile kombine kemik çalışmalarında da kullanılmıştır (Odacı ve ark., 2003). Bacınoğlu (2006) Kıvırcık koyunlarında, Demiraslan ve ark. (2015) Morkaraman ve Tuj koyunlarında yaptıkları çalışmalarda Cavalieri prensibini kullanarak metapodial hacim hesaplaması ile bir takım bulgular elde etmiştir. Bu çalışmada da literatür bilgisi dahilinde Hemşin koyun ırkında metapodium'ların morfometrik ve stereolojik olarak değerlendirilmesi amaçlanmıştır.

\section{Gereç ve Yöntem}

Çalışmada 1 yaşında 10 adet erkek Hemşin koyunu metapodium'u kullanıldı. Koyunların ağırlıkları ortalama $42 \mathrm{~kg}$ olarak belirlendi. Kemikler benzer besleme koşullarına sahip olması bakımından Ardanuç/Artvin'deki bir kasaptan temin edildi. Çalışma için gerekli izin Kafkas Üniversitesi Hayvan Deneyleri Yerel Etik Kurulu'ndan alındı (2015/122). Osteometrik ölçümlerden önce metapodium'lar 5 saat kaynatılıp, yağlarından arındırılmak üzere 12 saat \%50'lik hidrojen peroksitte bekletilerek masere edildi (Bacınoğlu, 2006) Maserasyondan sonra metapodium'lardan 16 morfometrik (Driesch, 1976; Guintard, 1998; Guintard ve Lallemand, 2003), 3 stereolojik toplam 19 adet ölçü alındı.

\section{Morfometrik ölçümler}

Maksimum uzunluk (GL), proximal ucun maksimum genişliği (Bp), metafiz’in maksimum derinliği (Be), metafiz'in maksimum genişliği (De), diafizin en küçük genişliği (SD), diafizin en küçük derinliği (DD), diafizin orta noktasının genişliği (d), diafizin orta noktasının derinliği (e), distal ucun maksimum genişliği (Bd), distal ucun derinliği (Dd), condylus lateralis'in internal trochlea'sının antero-posterior çapı (DIL), condylus lateralis'in eksternal trochlea'sının antero-posterior çap1 (DEL), condylus medialis'in internal trochlea'sının antero-posterior çapı (DIM), condylus medialis'in eksternal trochlea'sının antero-posterior çapı (DEM), condylus lateralis'in medio-lateral genişliği (WCL), condylus medialis'in medio-lateral genişliği (WCM) (Şekil 1, 2, 3, 4) 


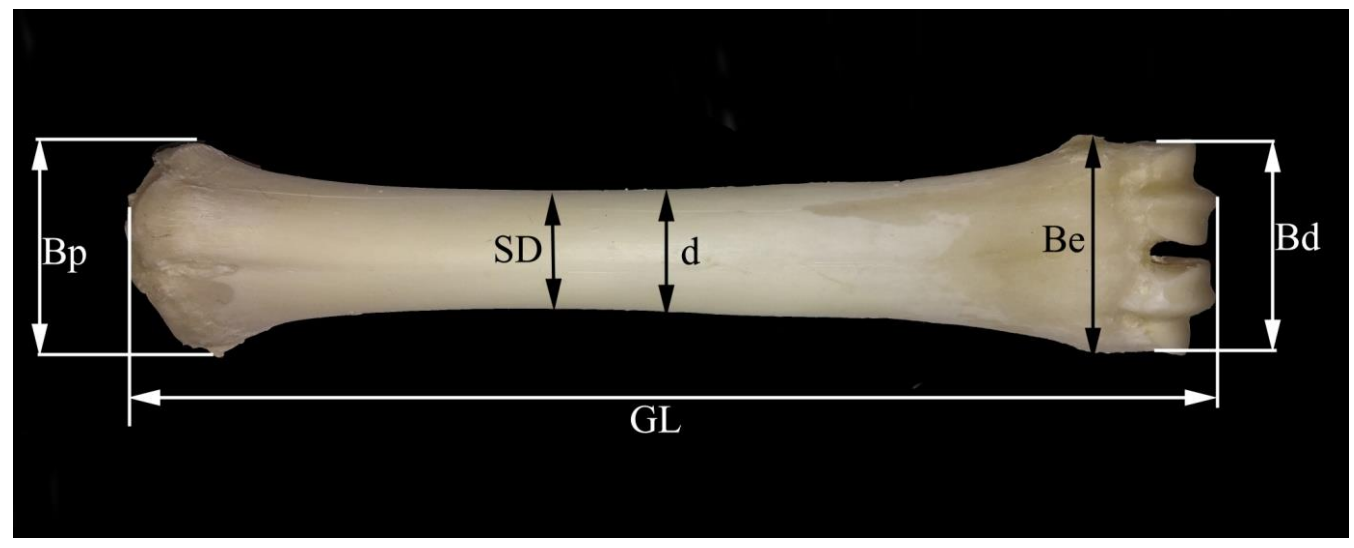

Şekil 1. Metatarsus’tan alınan morfometrik ölçüler (Dorsal görünüm)

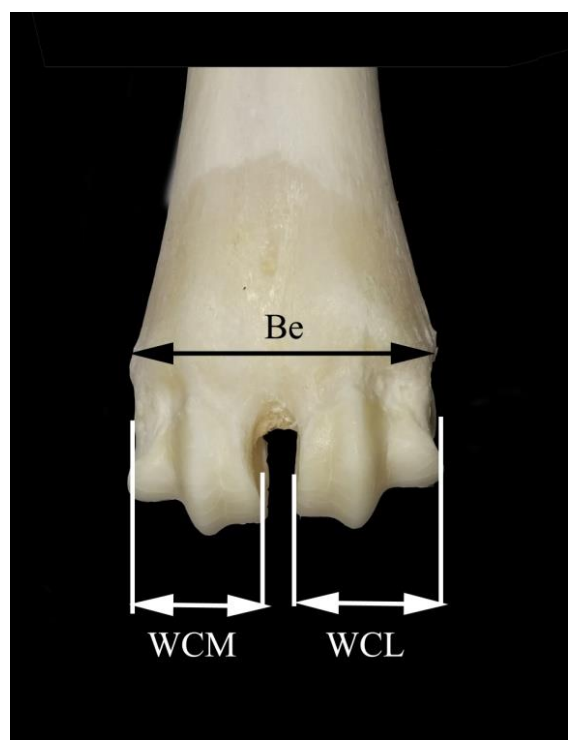

Şekil 2. Metatarsus'un distal'inden alınan morfometrik ölçüler (Dorsal görünüm)

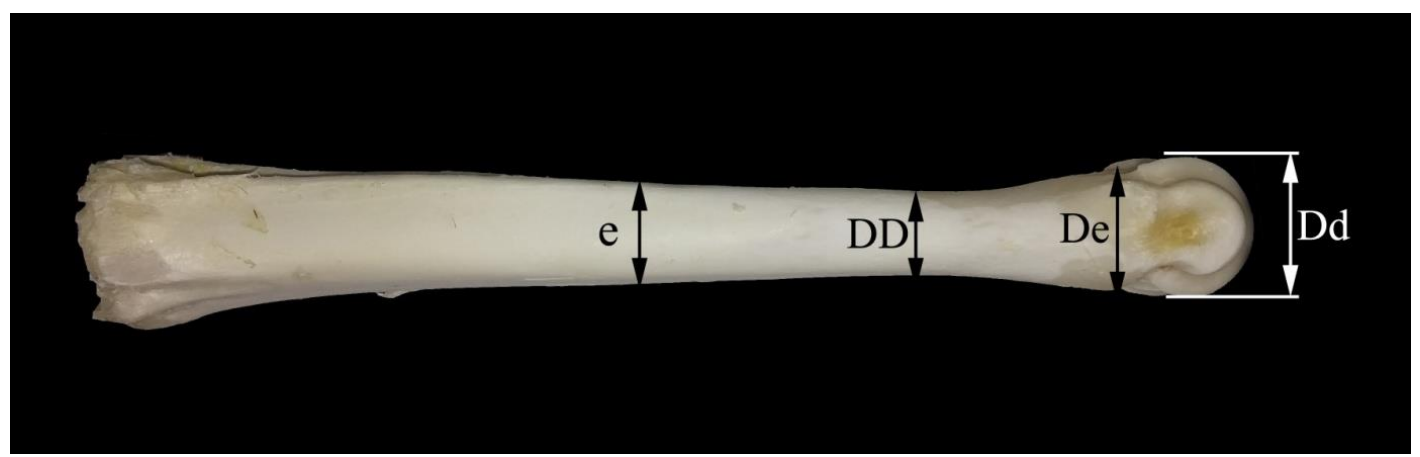

Şekil 3. Metatarsus’tan alınan morfometrik ölçüler (Lateral görünüm) 


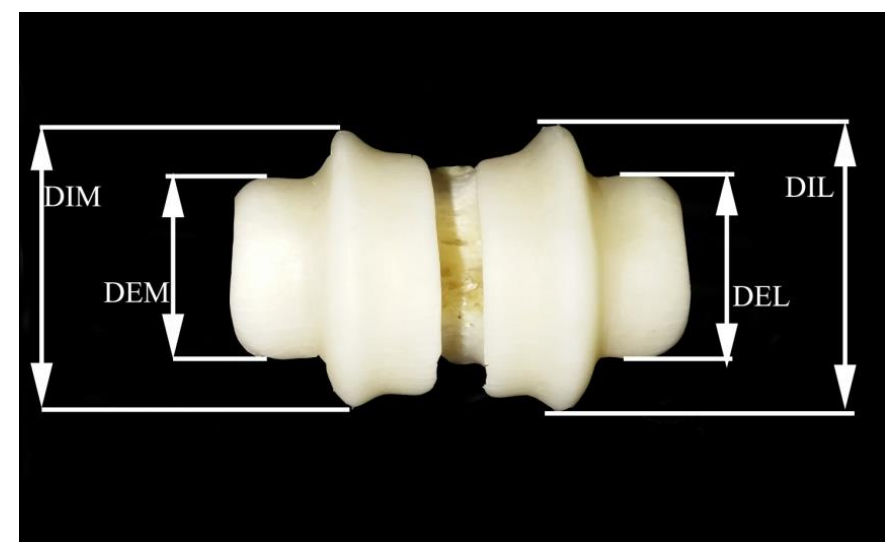

Şekil 4. Metatarsus'un distal'inden alınan morfometrik ölçümler (Distal görünüm)

Ayrıca metapodial ölçümlerden yararlanılarak faklılıkların değerlendirilmesi için metapodial incelik indeksi (SD / GL *100) (Berteaux ve Guintard, 1995; Davis, 2000; Guintard, 1998) ve metapodial indeks (DEM / Dd *100) (Guintard, 1998; Lallemand, 2002) hesapland1.

\section{Stereolojik ölçümler}

Stereolojik olarak cavum medullare ve kemik hacmi Cavalieri prensibi kullanılarak ölçüldü. Elde edilen bu iki değer toplanarak tüm metapodial hacme ulaşıldı. Stereolojik ölçümleri için öncelikle metapodium'lar elektrikli testere makinesi yardımıyla transversal olarak 0.5 cm kesit kalınlığında dilimlendi (Bacınoğlu, 2006). Dilimleme işlemini takiben her kesit sırasıyla numaralandırıldı. Kesitler düz bir zemin üzerine konularak $90^{\circ}$ açıyla fotoğraflandı (Canon 600D). Fotograflar ayrı ayrı Image J programında nokta sayım işlemine tabi tutuldu (Şekil 5).

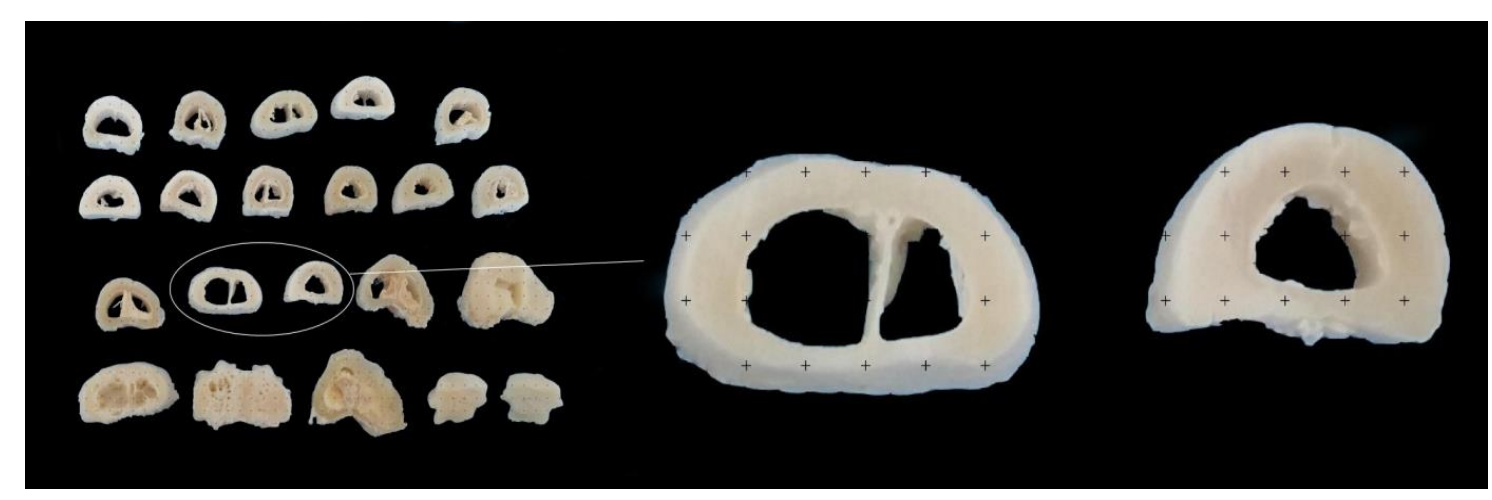

Şekil 5. Kesitler üzerinde nokta sayım işlemi. 
Nokta sayım işleminden sonra aşağıdaki formül kullanılarak hem medullar hacim, hem de kemik doku hacmi belirlendi (Gundersen ve Jensen, 1987; Gundersen, 1977; Gundersen, 1986).

$$
\begin{aligned}
& V=t \times[((S U) \times d) / S L]^{2} \times \Sigma P \\
& \text { V: Hacim } \\
& \text { t: Kesit kalınlığ }(0.5 \mathrm{~cm})
\end{aligned}
$$

SU: Görüntü büyütmesini gösteren skalanın temsil ettiği uzunluk

d: noktalı alan ölçüm cetvelindeki iki nokta arasındaki mesafeyi

SL: Görüntüdeki skalanın cetvel ile ölçülen uzunluğu

$\Sigma$ P: Sayılan toplam nokta sayısı

Hesaplanan hacimin doğruluğunu sorgulama amacıyla aşağıdaki formüller kullanılarak hata katsayısı (CE) hesaplandı.

1. Noise $=0.0724 \times(b / \sqrt{ } a) \times \sqrt{ } n \times \Sigma P$

Noise: Karmaşıklık (Noise) değeri

$\mathrm{b} / \sqrt{ } \mathrm{a}$ : Standart değer

n: Kesit sayıs1

$\Sigma$ P: Sayılan toplam nokta sayıs1

2. $\operatorname{VarSRS}_{S}\left(\sum_{i=1}^{n} a\right)=\left(3 x \sum\left(P_{i}{ }^{2}-\right.\right.$ Noise $\left.)-4 x \sum P_{i} x P_{i+1}+\sum P_{i} x P_{i+2}\right) / 12$

VarsRs: Toplam alan değişimi

$\sum_{i=1}^{n} a:$ n sayıdaki kesitte ortaya çıkan toplam alan değişim

$\sum$ Pi: i numaralı kesitte sayılan nokta sayısı

3. $C E\left(\sum P\right)=\frac{\sqrt{\text { Toplam varyans }}}{\sum^{P}}$

Toplam varyans $=$ Noise + VarsRS

P: Nokta say1s1

CE değerinin çalışmada güvenilirlik sınırı olan \% 10‘un altında olmasına dikkat edildi. 


\section{İstatistiksel Analiz}

Çalışmada elde edilen ölçümler ve hesaplamaların tanımlayıcı değerlerin (ortalama$\mathrm{x}$, standart sapma-SD) ve metapodium'lardan alınan ortalama değerlerin analizleri için SPSS istatistik paket programinda (16.0 version) non-parametrik bir test olan independent samples t testi $(\mathrm{P}<0.05)$ uyguland1. Ayrica veriler aynı programda Pearson's korrelasyon testine de tabi tutuldu. Elde edilen verilerden morfometrik değerler için varyasyon katsayısı (\%CV) hesapland1.

\section{Bulgular}

Çalışmada metacarpus ve metatarsus'tan alınan morfometrik veriler ve varyasyon katsayıları (\%CV) Tablo 1'de, stereolojik veriler Tablo 2'de gösterildi. Buna göre maksimum uzunluk metacarpus'ta ortalama $134.40 \mathrm{~mm}$, metatarsus'ta ortalama 139.16 $\mathrm{mm}$ olarak belirlendi. Stereolojik verilerine göre, metacarpus hacmi ortalama $26.88 \mathrm{~cm}^{3}$, metatarsus hacmi ortalama $36.39 \mathrm{~cm}^{3}$ olarak tespit edildi. Metacarpus ve metatarsus toplam kemik hacmi $(\mathrm{TH})$ ve kemik hacmi (KH) bakımından karşılaştırıldığında farkın istatistiksel olarak önemli olduğu $(\mathrm{P}<0.01)$, medullar hacmin $(\mathrm{MH})$ ise istatistiksel olarak anlam taşımadığı tespit edildi ( $\mathrm{P}>0.05)$.

Çalışmada hesaplanan varyasyon katsayısı değerlerine göre metacarpus’ta \%CV değerinin 1.51 ile 6.81 arasında, metatarsus'ta 1.42 ile 6.57 arasında değiştiği görüldü. Metacarpus'ta Bp, metatarsus'ta DEM değerlerinin en yüksek varyasyon katsayısına sahip olduğu tespit edildi.

Çalışmada metapodial parametrelerin birbirleriyle olan ilişkilerini belirlemek amacıyla korrelasyon analizi yapıldı ve elde edilen bulgular Tablo 3'te sunuldu. Buna göre $\mathrm{P}<0.01$ ve $\mathrm{P}<0.05$ açısından metacarpus'larda sırasıyla \% 9.2 ve $\% 12.6$, metatarsuslarda \%12.6 ve \%13.4 oranında istatistiksel olarak anlamlı sonuç bulundu. Hem metacarpus hem de metatarsus'ta SD-d, DEM-DIL, DIL-Dd, DIM-Dd, DIM-DIL parametreleri aralarında kuvvetli pozitif korelasyon olduğu tespit edildi. 
Tablo 1. Metapodium uzunluk değerleri ve varyasyon katsayısı (\%CV).

\begin{tabular}{|c|c|c|c|c|}
\hline $\begin{array}{l}\text { Morfometrik } \\
\text { ölçümler }\end{array}$ & $\begin{array}{l}\text { Metacarpus } \\
(\mathrm{x} \pm \mathrm{SD} \mathbf{~ m m})\end{array}$ & $\begin{array}{c}\text { Metacarpus } \\
\% \mathrm{CV} \\
\end{array}$ & $\begin{array}{l}\text { Metatarsus ( } \pm \text { SD } \\
\mathbf{m m} \text { ) }\end{array}$ & $\begin{array}{c}\text { Metatarsus } \\
\% \mathrm{CV} \\
\end{array}$ \\
\hline GL & $134.40 \pm 7.13$ & 5.30 & $139.16 \pm 6.17$ & 4.43 \\
\hline Bp & $27.14 \pm 1.85^{* *}$ & 6.81 & $23.15 \pm 1.50^{* *}$ & 6.47 \\
\hline Be & $27.09 \pm 0.73 * *$ & 2.69 & $25.63 \pm 0.56 * *$ & 2.18 \\
\hline De & $14.96 \pm 0.29$ & 1.93 & $15.04 \pm 0.68$ & 4.52 \\
\hline SD & $15.10 \pm 0.34 * *$ & 2.25 & $13.56 \pm 0.47 * *$ & 3.46 \\
\hline DD & $11.21 \pm 0.26^{* *}$ & 2.31 & $10.68 \pm 0.31 * *$ & 2.90 \\
\hline d & $15.50 \pm 0.30 * *$ & 1.93 & $15.31 \pm 0.61 * *$ & 4.45 \\
\hline $\mathbf{e}$ & $11.51 \pm 0.22 * *$ & 1.91 & $13.08 \pm 0.82 * *$ & 6.26 \\
\hline Bd & $29.00 \pm 0.44 * *$ & 1.51 & $27.51 \pm 0.83^{* *}$ & 3.01 \\
\hline Dd & $17.64 \pm 0.69$ & 3.91 & $17.67 \pm 0.50$ & 2.82 \\
\hline DIL & $17.59 \pm 0.48$ & 2.72 & $17.15 \pm 0.67$ & 3.90 \\
\hline DIM & $16.71 \pm 0.81$ & 5.2 & $16.31 \pm 0.67$ & 4.1 \\
\hline DEL & $11.39 \pm 0.77 * *$ & 6.76 & $10.35 \pm 0.63 * *$ & 6.08 \\
\hline DEM & $12.33 \pm 0.74 * *$ & 6 & $12.26 \pm 0.74 * *$ & 6.57 \\
\hline WCL & $12.52 \pm 0.45^{* *}$ & 3.59 & $11.40 \pm 0.39 * *$ & 3.42 \\
\hline WCM & $13.01 \pm 0.41 *$ & 3.30 & $12.65 \pm 0.18 *$ & 1.42 \\
\hline
\end{tabular}

$* *: \mathrm{P}<0.01, *: \mathrm{P}<0.05$

Tablo 2. Metapodium'ların stereolojik değerleri

\begin{tabular}{|c|c|c|}
\hline Stereolojik ölçümler & $\begin{array}{l}\text { Metacarpus } \\
\left(\mathrm{x} \pm \mathrm{SD} \mathrm{cm}^{3}\right)\end{array}$ & $\begin{array}{r}\text { Metatarsus } \\
\left(\mathrm{x} \pm \mathrm{SD} \mathbf{c m}^{3}\right)\end{array}$ \\
\hline Kemik hacmi & $23.39 \pm 0.44 * *$ & $31.58 \pm 0.56 * *$ \\
\hline Medulla hacmi & $3.49 \pm 0.11$ & $4.81 \pm 0.19$ \\
\hline Toplam hacim & $26.88 \pm 0.51 * *$ & $36.39 \pm 0.70 * *$ \\
\hline
\end{tabular}

$* *: \mathrm{P}<0.01$ 
The Morphometric and Stereologic Investigation of Metapodium in Male Hemshin Sheep

Tablo 3. Metacarpus ve metatarsus'un morfometrik ölçümlerine ait korelasyon verileri

\begin{tabular}{|c|c|c|c|c|c|c|c|c|c|c|c|c|c|c|c|c|}
\hline $\mathbf{M C} \rightarrow$ & GL & Bp & $\mathbf{B e}$ & De & SD & DD & d & e & Bd & dd & DIL & DIM & DEL & DEM & WCL & WCM \\
\hline GL & & ,590 & ,479 &,- 037 & ,111 & ,387 &,- 038 & ,410 & ,727* & ,660* &, $845^{* *}$ & ,777 ${ }^{* * *}$ & ,523 & ,649* & ,084 & ,288 \\
\hline Bp & ,354 & & ,530 &,- 181 & ,057 & ,378 & ,012 & ,392 & ,749* & ,570 & ,731* & ,494 & , 162 & ,622 & ,136 & , 455 \\
\hline Be & ,607 & ,591 & &,- 110 & ,490 & ,386 & ,471 & ,066 &, $794^{* *}$ & ,363 & ,326 & ,231 &,- 236 & ,247 & ,713* &, $959^{* *}$ \\
\hline De & ,246 & ,553 & ,071 & & ,121 & ,408 &,- 185 & , 456 &,- 281 & ,282 & ,112 & , 192 & ,437 & ,504 & ,307 & ,006 \\
\hline SD & ,223 & ,357 & ,614 &,- 418 & & ,271 &, $\mathbf{7 7 0}^{* * *}$ &,- 103 & ,158 & ,143 &,- 065 & ,008 &,- 221 &,- 135 &, $665^{*}$ & ,534 \\
\hline DD & ,340 & ,509 & ,446 & ,504 & ,202 & & ,381 & ,639" & ,426 & ,697* & ,438 & ,632 & ,340 & ,573 & ,431 & ,405 \\
\hline d & ,403 &,- 020 & ,528 &,- 450 &, $782^{* *}$ & ,030 & &,- 025 & ,308 & ,061 &,- 202 & ,004 &,- 282 &,- 369 & ,582 & ,534 \\
\hline e & ,334 & ,154 &, 526 &,- 388 & ,759* & ,526 &, $655^{*}$ & & ,291 & ,545 & ,546 & ,540 &, $836^{* *}$ & ,745* & ,021 & ,012 \\
\hline Bd & ,463 & ,436 &, $768^{* *}$ &,- 147 & ,738 & ,411 &, $764^{*}$ & ,759" & & ,579 &, $678^{*}$ & 609 & ,108 & ,400 & ,346 & ,708* \\
\hline Dd & ,695* &, $\mathbf{7 7 0}^{* *}$ & ,444 & ,679* & ,138 &, $673^{*}$ &,- 020 & ,235 & ,344 & &, $875^{* *}$ &, $917^{* * *}$ & ,487 & ,740* & ,028 & ,300 \\
\hline DIL & ,506 &, $861^{* *}$ & ,519 & ,395 & ,432 & ,631 & ,119 & ,467 & ,582 &, $\mathbf{8 7 7} 7^{\text {** }}$ & &, $895^{* * *}$ & ,600 &, $\mathbf{8 1 3}^{* *}$ &,- 116 & ,199 \\
\hline DIM & ,376 &, $868^{* *}$ & ,564 & ,636 & ,222 &, $\mathbf{7 8 3}^{* *}$ &,- 036 & ,320 & ,531 &, $\mathbf{8 3 3}^{* * *}$ &, $\mathbf{8 8 4}^{* * *}$ & & ,615 & ,674* &,- 062 & , 147 \\
\hline DEL & ,096 &, $\mathbf{8 0 2}^{* *}$ &, 551 & ,424 & ,477 & ,709* & , 147 & ,361 &, 524 & ,508 & ,659" &, $\mathbf{7 8 2}^{* * *}$ & & ,667* &,- 291 &,- 342 \\
\hline DEM & ,281 &, $675^{*}$ & ,420 & ,311 & ,474 &, $847^{* * *}$ & , 169 &, $669^{*}$ & ,596 & ,707* &, $865^{* *}$ &, $\mathbf{8 3 8}^{\text {** }}$ &, $777^{* *}$ & & ,045 & ,162 \\
\hline WCL &,- 161 &,- 087 & ,333 &,- 348 & ,488 & ,330 & ,517 & ,623 & ,638* &,- 170 & ,086 & ,187 & ,266 & ,349 & &, $\mathbf{8 2 5}{ }^{\text {** }}$ \\
\hline WCM & , 194 &,- 306 & ,151 &,$- 656^{*}$ & ,368 & ,026 & ,480 & ,558 & ,366 &,- 246 &,- 071 &,- 274 &,- 074 & ,070 & ,339 & \\
\hline
\end{tabular}

$*: \mathrm{P}<0.05, * *: \mathrm{P}<0.01$ 
Çalışmada metapodial incelik indeksi metatacarpus için 11.26, metatarsus için 9.74 olarak bulundu. Metapodial indeks ise metacarpus için 69.89, metatarsus için 69.38 olarak belirlendi.

\section{Tartışma}

Hemşin koyunu sayısının son yıllarda çeşitli nedenlerle azaldığı ve ırkın yok olma tehlikesi ile karşı karşıya kaldığı bildirilmektedir (Anonim, 2009; Anonim, 2010). Bu nedenle mezbahada dişi Hemşin koyunu kesimi sınırlandırılmıştır. Bundan dolayı çalışmada metapodium'ların cinsiyet yönünden farklılıkları değerlendirilememiştir. Dolayısıyla araştırmada sadece erkek Hemşin koyununun metapodiumları morfometrik ve stereolojik yönden incelendi.

Çalışmada değişkenliği belirlemek amacıyla morfometrik verilerin varyasyon katsayısı hesaplandı. Buna göre \%CV değerlerinin metacarpus'ta 1.51 ile 6.81 arasında, metatarsus'ta 1.42 ile 6.57 arasında değiştiği görüldü. Demiraslan ve ark. (2015) \%CV değerini erkek Morkaraman koyunu metacarpus'unda 2.03 ile 9.71, metatarsus'unda 1.27 ile 6.50 arasinda, erkek Tuj koyunu metacarpus'unda 3.16 ile 14.22 arasinda, metatarsus'unda 2.31 ile 9.30 arasında değiştiğini bildirmişlerdir. Lallemand (2002) bu değerleri erkek koyunda metacarpus ve metatarsus'ta sırasıyla 9.97 - 19.61 ve 12.91 - 18.54 arasında değiştiğini rapor etmiştir. Guintard ve Lallemand (2003) erkek koyunda \%CV değerini metacarpus ve metatarsus'ta sırasıyla 9.97 - 19.61 ve 12.91 - 18.54 arasında değiştiğini belirtmişlerdir. Pazvant ve ark. (2015) bu değerin metacarpus ve metatarsus'ta sirasıyla 8.4 - 12.03 ve $5.91-8.49$ arasinda olduğunu bildirmişlerdir. Onar ve ark. (2008) ise \%CV değerinin metacarpus ve metatarsus'ta sırasıyla 4.13 - 7.84 ve 5.45 - 9.36 arasında değiştiğini rapor etmişlerdir. Literatür ile karşılaştırma yapıldığında elde edilen verilerin, Lallemand (2002), Guintard ve Lallemand (2003), Pazvant ve ark. (2015)'ın belirttiği verilerden daha düşük, Demiraslan ve ark. (2015) ve Onar ve ark. (2008)'ın belirttiği verilere benzer ortalamaya sahip olduğu gözlendi.

Onar ve ark. (2008) arkeolojik kazılardan elde edilen koyun ve keçi metapodiumları üzerinde yaptığı osteometrik çalışmada yetişkin koyun metacarpus'unda en yüksek ve düşük \%CV değerinin sirasiyla De ve Bd'ye, metatarsus'unda DD ve Bd'ye ait olduğunu belirtmiştir. Aynı çalışmada yetişkin keçi metacarpus’unda en yüksek ve düşük \%CV değerinin sırasıyla GL ve Bd'ye, metatarsus'ta DD ve Bd'ye ait olduğu bildirilmiştir. Pazvant ve ark. (2015) yaptığı çalışmasında koyun metacarpus'unda en yüksek ve düşük \%CV 
değerinin DD ve Dp (Bu değer çalışmamızda ölçülmedi)'ye, metatarsus'unda DD ve Bd'ye ait olduğunu belirtmiş̧lerdir. Aynı çalışmada \%CV değeri keçi metacarpus'unda Bd ve WCM, metatarsus'unda De ve DIL'a aitti. Demiraslan ve ark. (2015) Morkaraman koyunu metacarpus'unda en yüksek ve en düşük \%CV değerinin De ve Bp'ye, metatarsus'unda Be ve DIM'a ait olduğu, Tuj koyununda metacarpus için en yüksek ve düşük \%CV değeri De ve DD, metatarsus için WCM ve Bp'ye ait olduğunu bildirmişlerdir. Yapılan çalışmada ise en yüksek ve en düşük \%CV değeri metacarpus’ta $\mathrm{Bp}$ ve Bd'ye, metatarsus'ta ise DEM ve WCM'ye aitti.

Onar ve ark. (2008) yaptığı çalışmada koyun metacarpus ve metatarsus incelik indeksini sırasıyla 11.06 ve 9.18, keçi metacarpus ve metatarsus incelik indeksini sırasıyla 15.02 ve 11.57 olarak belirtmişlerdir. Pazvant ve ark. (2015) yaptığı çalışmada koyun metapodial incelik indeksini metacarpus ve metatarsus'ta sırasıyla 11.70 ve 9.45 , keçi metacarpus ve metatarsus'unda 14.89 ve 11.11 olarak rapor etmişlerdir. Demiraslan ve ark. (2015) Morkaraman koyunu metacarpus ve metatarsus incelik indeksini sirasiyla 10.48 ve 8.84, Tuj koyunu metacarpus ve metatarsus incelik indeksini sirasiyla 10.05 ve 9.08 olarak tespit etmişlerdir. Çalışmamızda Hemşin koyununda metacarpus ve metatarsus incelik indeksi 11.26 ve 9.74 olarak belirlendi. Elde edilen verilerin literatür (Onar ve ark., 2008; Pazvant ve ark., 2015; Demiraslan ve ark., 2015) bulguları ile benzeştiği görülmektedir.

Çalışmada elde edilen verilerin birbirleriyle olan ilişki derecelerini belirlemek amacıyla korelasyon analizi yapıldı. Buna göre hem metacarpus hem de metatarsus'ta SD-d, DEM-DIL, DIL-Dd, DIM-Dd, DIM-DIL parametreleri aralarında kuvvetli pozitif korelasyon olduğu tespit edildi $(\mathrm{P}<0.05)$. Demiraslan ve ark. (2015) yaptıkları çalışmada erkek morkaraman metatartus'unda DIL-Dd, metacarpus'unda DIL-DIM arasındaki korelasyon değerini ve erkek Tuj koyunu metacarpus'unda SD-d, metatarsus'unda DEM-DIL parametreleri arasındaki korelasyon değerinin kuvvetli pozitif olduğunu bildirmişlerdir $(\mathrm{P}<$ 0.05). Demiraslan ve ark. (2015)'nın yaptıkları çalışmada belirtilen parametreler arasındaki korelasyon değerleri erkek Hemşin koyunu ile benzerlik göstermektedir.

Çalışmada belirlenen morfometrik veriler literatür bilgisiyle karşılaştırmalı olarak Tablo 4 ve 5'te sunuldu. Buna göre Hemşin koyunu metacarpus ve metatarsus'undan alınan morfometrik ölçülerin genel olarak Demiraslan ve ark. (2015), Bacınoğlu (2006), Guintard ve Lallemand (2003) ile benzerlik gösterdiği, Pazvant ve ark. (2015) ve Onar ve ark. (2008)'nın 
bulgularından daha fazla olduğu, Pourlis ve ark. (2017)'nın bulgularından ise daha az olduğu görülmektedir.

Çakır ve ark. (1998) karaca metapodium'unda yaptığı çalışmasında metacarpus'ta e ve d değerlerini sırasıyla 12.93 ve $14.10 \mathrm{~mm}$, metatarsus'ta 16.27 ve $12.71 \mathrm{~mm}$ olarak belirtmişlerdir. Çalışmamızda ise bu değerler metacarpus'ta 11.51 ve $15.50 \mathrm{~mm}$, metatarsus'ta 13.08 ve 15.31 olarak belirlenmiştir. $\mathrm{Bu}$ değerler karaca metatarsus'unun erkek Hemşin koyunu metatarsus'una göre dorsoplantar yönde daha geniş olduğunu göstermektedir.

Tablo 4. Hemşin koyunu metacarpus morfometrik ölçülerinin $(\mathrm{mm})$ literatür bulguları ile karşılaştırılması.

\begin{tabular}{|c|c|c|c|c|c|c|c|c|}
\hline & & $\begin{array}{r}\text { Demiraslan } \\
(2015)\end{array}$ & e ark. & $\begin{array}{c}\text { Bacınoğlu } \\
(2006)\end{array}$ & $\begin{array}{c}\text { Onar ve } \\
\text { ark. } \\
(2008)\end{array}$ & $\begin{array}{c}\text { Pourlis ve } \\
\text { Ark. } \\
(2017)\end{array}$ & $\begin{array}{l}\text { Guintard } \\
\text { ve } \\
\text { Lamelland } \\
(\mathbf{2 0 0 3 )}\end{array}$ & $\begin{array}{c}\text { Pazvant } \\
\text { ve } \\
\text { ark. } \\
(2015)\end{array}$ \\
\hline & $\begin{array}{c}\text { Erkek } \\
\text { Hemşin } \\
\text { koyunu }\end{array}$ & $\begin{array}{c}\text { Morkaraman } \\
\text { koyunu }\end{array}$ & $\begin{array}{c}\text { Tuj } \\
\text { koyunu }\end{array}$ & $\begin{array}{c}\text { Erkek } \\
\text { Kivırcık } \\
\text { koyunu } \\
\end{array}$ & Koyun & Koyun & $\begin{array}{l}\text { Erkek } \\
\text { koyun }\end{array}$ & Koyun \\
\hline GL & 134.40 & 135.37 & 133.48 & 129.03 & 122.72 & 149.71 & 133 & 124.91 \\
\hline Bp & 27.14 & 27.25 & 26.29 & 27.34 & 23.29 & 27.09 & 28.9 & 24.51 \\
\hline d & 15.50 & 14.61 & 15.10 & 14.47 & - & 16.71 & 18 & 14.71 \\
\hline e & 11.51 & 11.48 & 11.54 & 10.88 & 10.33 & 12.28 & 12.1 & 10.98 \\
\hline SD & 15.10 & 14.20 & 14.70 & 14.04 & 13.55 & 16.06 & 17.4 & 14.56 \\
\hline DD & 11.21 & 10.91 & 10.88 & 10.68 & 9.28 & 11.59 & 11.3 & 9.98 \\
\hline Bd & 29 & 28.44 & 28.20 & 29.02 & 25.12 & 29.01 & 30.6 & 26.74 \\
\hline De & 14.96 & 14.09 & 14.70 & 16.70 & 13.63 & 15.25 & 16.4 & 14.10 \\
\hline Be & 27.09 & 30.57 & 29.71 & 31.03 & 25.20 & 29.58 & 32.4 & 27 \\
\hline Dd & 17.64 & 17.50 & 17.58 & 19.13 & 16.16 & 18.79 & 19.2 & 16.42 \\
\hline DEM & 12.33 & 13.25 & 13.17 & 13.13 & - & 12.71 & 13 & 11.98 \\
\hline DIM & 16.71 & 18.96 & 18.60 & 15.93 & - & 15.76 & 16.1 & 14.24 \\
\hline DEL & 11.39 & 12.23 & 12.28 & 11.90 & - & 12.12 & 12.2 & 11.06 \\
\hline DIL & 17.59 & 18.19 & 18.57 & 15.89 & - & 15.80 & 16.1 & 14.32 \\
\hline WCM & 13.01 & 13.58 & 13.84 & 13.95 & - & 13.61 & 14 & 12.66 \\
\hline WCL & 12.52 & 12.87 & 13.41 & 13.32 & - & 12.94 & 13.5 & 12.14 \\
\hline
\end{tabular}

Çalışmamızda stereolojik bir hacim hesaplama yöntemi olan Cavalieri Prensibi kullanılarak metapodiumların cavum medullare ve kemik doku hacmi hesaplandı. Oransal olarak bakıldığında Bacınoğlu (2006) dişi Kıvırcık koyunu metacarpus ve metatarsus'unda MH/TH değerini \%13.39 ve \%12.27, erkek Kıvırcık koyunlarında \%16.19 ve \%15.28 olarak bildirmiştir. Başka bir çalışmada (Demiraslan ve ark., 2015) ise bu değerler metacarpus ve metatarsus için sırasıyla dişi Morkaraman koyununda \%18.49 ve \%19.32, erkek Morkaraman koyununda \%18.37 ve \%18.59, dişi Tuj koyununda \%19.86 ve \%19.01, erkek Tuj koyununda 
\%17.12 ve \%18.41 olarak belirlenmiştir. Bu değer çalışmamızda metacarpus ve metatarsus’ta sirasıyla \%12.98 ve \%13.21 olarak tespit edildi. Bu durumda Tuj, Morkaraman ve erkek Kıvırcık ırkı koyunlarının metapodium'unda, erkek Hemşin koyunu metapodium'una göre daha fazla kemik iliği bulunabileceği söylenebilir.

Tablo 5. Hemşin koyunu metatarsus morfometrik ölçülerinin (mm) literatür bulguları ile karşılaştırılması.

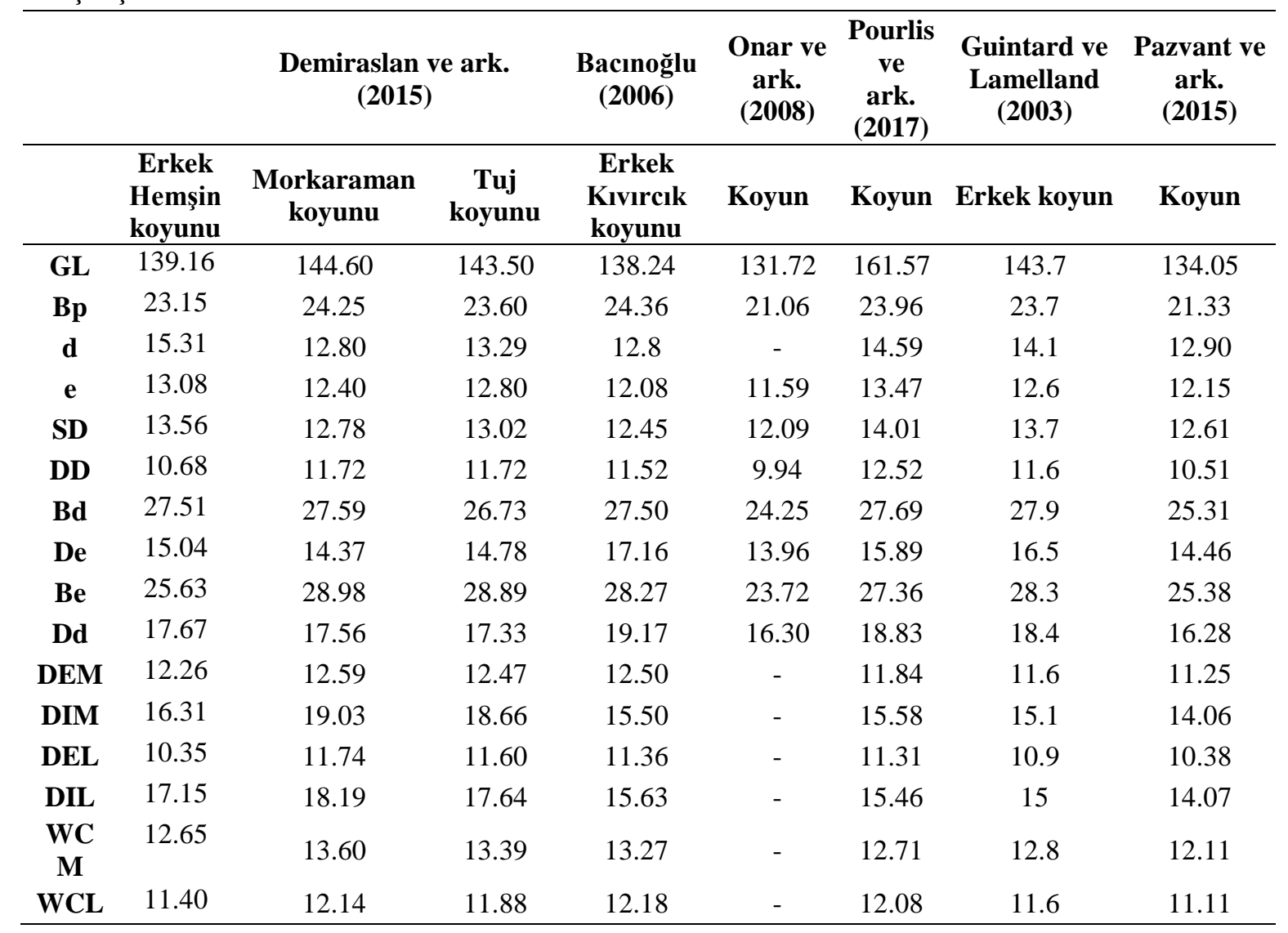

Sonuç olarak çalışmada Türkiye'nin Doğu Karadeniz Bölgesi'nde küçükbaş hayvan yetiştiriciliği içinde kendine yer bulmuş Hemşin koyun 1rklarında metapodium'ların morfometrik ve stereolojik yönleri değerlendirilmiş, ortalama değerlerin neler olduğu ortaya konularak, referans değerler elde edilmiştir. Ayrıca verilerin varyasyon katsayıları da hesaplanarak etki faktörlerine göre değişim dereceleri belirlenmiştir. Bulgular literatürdeki diğer koyun ırklarıyla karşılaştırılmıştır. Belirtilen bu çıkarımlarla birlikte çalışmanın literatüre destek sağlayacağı düşünülmektedir. 


\section{Kaynaklar}

1. Alpak, H., Onar, V., Mutuş, R., 2009. The relationship between morphometric and long bone measurements of the Morkaraman sheep. Turkish Journal of Veterinary Animal Sciences 33, 199-207.

2. Anonymous, 2010. Artvin Provincial Directorate of Agriculture. Annual Data http://www.artvintarim.gov.tr/ (Erişim 10.10.2010).

3. Anonymous, 2009. Tarım ve Köyişleri Bakanlığg Tarımsal Araştırmalar Genel Müdürlüğü Büyükbaş ve Küçükbaş Hayvancılık Araştırmaları Program Değerlendirme Toplantısı ara raporu 1, 197-2001.

4. Avendano, C., Roda, J.M., Carceller, F., DiezTejedor, E., 1995. Morphometric study of focal cerebral ishemia in rats: a stereological evaluation. Brain Research 673 (1), 83-92.

5. Bacınoğlu D, 2006. Kıvırcık 1rk1 koyunlarda metapodium'ların morfometrik ve stereolojik metodlarla incelenmesi. Doktora Tezi, İstanbul Üniversitesi Sağlık Bilimleri Enstitüsü, İstanbul.

6. Berteaux, D., Guintard, C., 1995. Osteometric study of the metapodials of Amsterdam Island feral cattle. Acta Theriologica 40, 97-110.

7. Boessneck, J., 1969. Osteological differences between sheep (Ovis aries Linne) and goat (Capra hircus Linne). In: Brothwell D and Higgs E, editor. Science in Archaeology. London, pp. 331-358.

8. Brokees, P.M., Hanks, J., Ludbrook, J.V., 1977. Bone marrow as a index of condition in African ungulates. South African Journal of Wildlife Research 7, 61-66.

9. Currey, J.D., 2002. Bone structure and mechanics. Princeton: Princeton Universty Press.

10. Çakır, A., Öğüt, İ., Kabak, M., 1998. Karacada metapodium ve capsula ungulae'nin makroanatomik ve morfometrik olarak incelenmesi. Ankara Üniversitesi Veteriner Fakültesi Dergisi 45, 229-238.

11. Davis, S.J.M.: Measurements a group of adult female shetland sheep skeletons from a singlenflock: a baseline for zooarchaeologists. Journal of Archaeological Science, 23: 593-612, 1996.
12. Davis, S.J.M., 2000. The effect of castration and age on the development of the Shetland sheep skeleton and a metric comparison between bones of males, females and castrates. Journal of Archaeological Science 27, 373-390.

13. Demiraslan, Y., Gürbüz, İ., Aslan, K., Akbulut, Y., 2015. The stereological and morphometrical analysis of metapodium in Tuj and Morkaraman sheep. Arc Journal of Animal and Veterinary Sciences 1(1), 12-23.

14. Driesch, A.V.D., 1976. A guide to the measurements of animal bones from Archaeological Sites. Harvard Peabody Museum Bulletins 1, 1-137.

15. Garcia-Finana, M., Cruz-Orive, L.M., Mackay, C.E., Pakkenberg, B., Roberts, N., 2003. Comparison of MR imaging against physical sectioning to estimate the volume of human cerebral compartments. NeuroImage 18 (2), 505516.

16. Guintard, C., Lallemand, M., 2003. Osteometric study of metapodial bones in sheep. Annals of Anatomy 185, 573-583.

17. Guintard, C., 1998. Osteometrie des metapodes de bovins. Revue de Medicine Veterinaire 149 (7), 751-770.

18. Gundersen, H.J.G., Jensen, E.B., 1987. The efficiency of systematic sampling in stereology and its prediction. Journal of Microscopy 147, 229-263.

19. Gundersen, H.J.G., 1977. Notes on the estimation of the numerical density of arbitrary particles: the edge effect. Journal of Microscopy $111,219-223$.

20. Gundersen, H.J.G., 1986. Stereology of arbitrary particles. A review of unbiased number and size estimators and the presentation of some new ones in memory of William R. Thompson. Journal of Microscopy 143, 3-45.

21. Lallemand, M., 2002. Etude osteometrique de metapodes de mouton (Ovis aries,L). $\mathrm{PhD}$ Thesis, Ecole Nationale Veterinaire de Nantes, Nantes.

22. Odac1, E., Şahin, B., Sönmez, O.F., Kaplan, S., Baş, O., Bilgiç, S., Bek, Y., Ergür, H., 2003. Rapid estimation of the vertebral body volume: a 
combination of the Cavalieri principle and computed tomography images. European Jounal of Radiology 48, 316-326.

23. Onar, V., Pazvant, G., Belli, O., 2008. Osteometric examination of metapodial bones in sheep (Ovis aries L.) and goat (Capra hircus L.) unearthed from the Upper Anzaf Castle in Eastern Anatolia. Revue de Medicine Veterinaire 159(3), 150-158.

24. Outram, A.K., 2002. Bone fracture and within bone nutrients: an experimentally based method for investigating levels of marrow extraction. In: Miracle P. and Milner N. Consuming passions and patterns of consumption. Chapter 6, MacDonald Institata Monographs Series, pp. 5163.

25. Outram, A.K., 2003. Levels of substince stres amongst norse settlers in Iceland and Greenland using Levels of bone fat exploitation as an indicator. Enviromental Archaeology 8, 119-128.

26. Pazvant, G., Onar, V., Alpak, H., Gezer İnce, N., Kahvecioğlu, K.O., Armutak, A., Kızıltan, Z.,
2015. Osteometric Examination of Metapodial Bones in Sheep (Ovis aries L.) and Goat (Capra hircus L.) Unearthed from the Yenikap1 Metro and Marmaray Excavations in Istanbul. Kafkas Üniversitesi Veteriner Fakültesi Dergisi 21, 147153.

27. Pourlis, A., Katsoulos, P., Chatzis, T.H., 2017. Metrical data of metapodial bones in female karaguoniko sheep and Helenic goat. Revue de Medicine Veterinaire 168, 10-12.

28. Rowley-Conwy, P., 1998. Improved separation of Neolithic metapodials of sheep (ovis) and goats (capra) from Arene Candide cave, Liguria, Italy. Journal of Archaeological Science, 25, 251-258.

29.Ziraatkent, 2018. Koyun 1rkları ve özellikleri. http://www.ziraatkent.com/koyun-irklari-veozellikleri/542/ (Erişim 20.02.2018). 